\title{
DESIGN OF AN INTELLIGENT AND EFFICIENT LIGHT CONTROL SYSTEM
}

\author{
Arun Radhakrishnan, \\ Department of ECE, \\ Jimma Institute of Technology, \\ Jimma University, \\ Ethiopia
}

\author{
Vuttaradi Anand, \\ Department of ECE, \\ Jimma Institute of Technology, \\ Jimma University, \\ Ethiopia
}

Abstract: Recently, many researches has been carried out to save the energy in many aspects such as producing a device which consumes very less energy or designing a system which helps to reduce the power consumption using the existing devices. In this paper, a room light control system is proposed which is named as light control system (LCS). This proposed system will able to provide the needed light which provides the satisfaction of users and will provide energy saving and management.

In this paper the Lighting Control System and the decision making algorithm, are discussed. As per the algorithm the system will first check any occupant is there in the room. If so then the system will check the intensity of light in the room and if it is low then it will switch on the light.

Our proposed system can able to minimize the energy consumed for lighting in a room and can able to provide it efficiently.

Keywords: Lighting Control system, Energy saving, LDR, PIR sensor

\section{INTRODUCTION:}

Power saving have became a necessary thing in our day to day life. Many conventional power saving methods such as using electrical devices which consumes very less energy or cutting off the entire power supply for a scheduled time for a particular area are not efficient and there will be a lot discomforts to the users and cost may also increase to use a low power electrical device.

Buildings are responsible for up to $40 \%$ of energy usage. Most part of this energy is used mainly for maintaining good lighting such that the workers feel comfortable. Nowadays the newly constructed modernised or automated buildings may have lighting system to improve the comfort of occupants and to save the energy. But there are large number of old buildings which contains the traditional lighting system. To reduce the energy consumption in those types of buildings and to help the owners of that building in terms of saving electricity bill an intelligent and an effective method is discussed in this paper.

Because of advancement in Sensor technology a very cheap and portable methods to measure our surroundings are available.

The amounts of light required to for a good environment to work comfortably in various areas are shown in table 1 which is recommended by CIBSE lighting guides.' 
Table 1 Required intensity of light for various environments

\begin{tabular}{|c|c|}
\hline $\begin{array}{c}\text { Type of place and } \\
\text { work }\end{array}$ & $\begin{array}{c}\text { Intensity } \\
\text { required }\end{array}$ \\
\hline Filing - Office work & 300 lux \\
\hline $\begin{array}{c}\text { General office (Typing } \\
\text { and Writing) }\end{array}$ & 500 lux \\
\hline Painting & 750 lux \\
\hline Classrooms & 300 lux \\
\hline $\begin{array}{c}\text { Classrooms for } \\
\text { evening class }\end{array}$ & 500 lux \\
\hline Auditorium & 500 lux \\
\hline Assembly ( Industry) & 1000 lux \\
\hline
\end{tabular}

\section{EXISTING SYSTEM:}

This section describes about the most commonly used lighting control system used in buildings. Since this method is going to use wireless sensor network it is mandatory to know the operation of existing lighting control system. It can be decided that energy loss is occurred with a lighting system when the lighting system illuminates a light which is an area which is not being used currently at that particular time or when it illuminates a light even though sufficient lighting is available to work.

The most commonly used lighting systems are explained below.

\subsection{A Switch operated manually:}

In this method a user has to switch $\mathrm{ON}$ and $\mathrm{OFF}$ the required lights. Since the user can switch on and off the lights as per their preferences there is a chance of keeping the lights in on state even though it was not need during that time. This may

This approach first checks whether any occupants are there in the room or not. If anybody is there in that room then it checks the intensity of light, if it is enough then it won't switch on the light otherwise it switch on the light.

\subsection{By Detecting Occupants:}

occur because of carelessness of user and a large amount of power is wasted.

The lighting system with occupant detection uses passive infrared sensor (PIR). This PIR sensor detects any movement is present in that particular area. If any movement is there means then this system automatically switches $\mathrm{ON}$ the lights. If timers are not used in this type of system means then the lights will be kept in ON state even after the user left the place. Because of this fault also a large amount of energy can be wasted.

Then another drawback about this type of system is, it will switch ON the lights when there is an occupant is present in that area. But there is a possibility of enough lighting will be there at that particular time. This system is not going to check the intensity of light before switching on the lights. Because of this also a large amount of energy can be lost.

\section{PROPOSED SYSTEM:}

The proposed system overcomes all the drawbacks of existing system. This system takes two things into account before taking any action, namely (1) human presence and (2) intensity of light. The system consists of a PIR sensor (Parallax 555- 28027) and an LDR (NORP 12). The PIR sensor is used to detect whether any occupants are there in that room and LDR is used to detect the intensity of light in that room. Apart from this an algorithm can be implemented in our system which uses both the LDR and PIR sensor to decide whether to switch on the light or not.

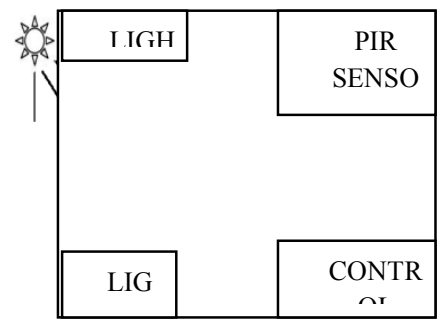

Figure 1 Setup of proposed system 


\section{SYSTEM DESIGN:}

\subsection{Block diagram:}

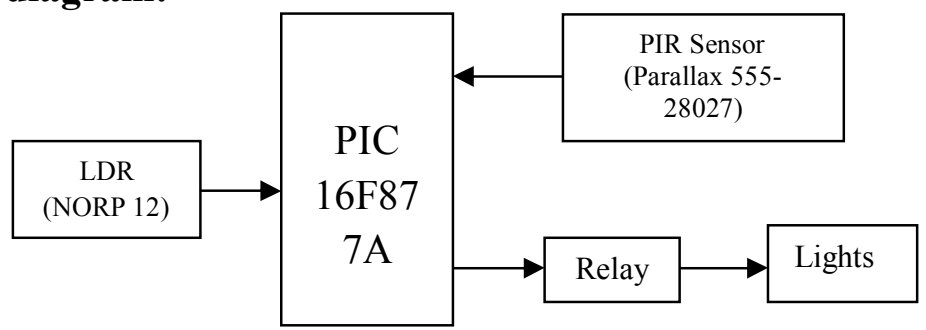

Figure 2 Block Diagram for the proposed system.

This system can be implemented using a PIC 16F877A, a LDR, A PIR sensor and the lights can be controlled by relays. The LDR sensor will keep on sensing the intensity of light and sends it to the microcontroller. The PIR sensor will send a signal to the microcontroller if there is any occupant in the room. If anybody is present in the room then the microcontroller compares the sensed value of intensity in the room with the value already stored in the microcontroller. If the sensed value is less than the value stored in the microcontroller then the light will be switched on by connecting the relay.

\section{ALGORITHM:}

Step 1: Start

Step 2: Check whether any occupant is there in the room using PIR sensor.

Step 3: If any Occupants is there means then compare the intensity of light in the room which was sensed by LDR. If nobody was there means then after some time delay again go to step 1 .

Step 4: If the sensed intensity is less than the required level, then switch on the light or if it was enough means then after some time delay proceed to step 1 .

As per the algorithm our system will first check whether any occupants are there in the room with the help of PIR sensor where the system has been installed. If any occupants are there then it will check the value of light luminance which is sensed through LDR and then the sensed value will be compared with the value stored in the microcontroller, if the value is less than the lights will be switched on or if the sensed value is greater than the stored value then it will wait for some time and again it will from the first.

While checking for occupants if no one is there in the room then the system will wait for some time (delay), which can be programmed in the microcontroller then it will start from the first step.

\section{FLOWCHART:}

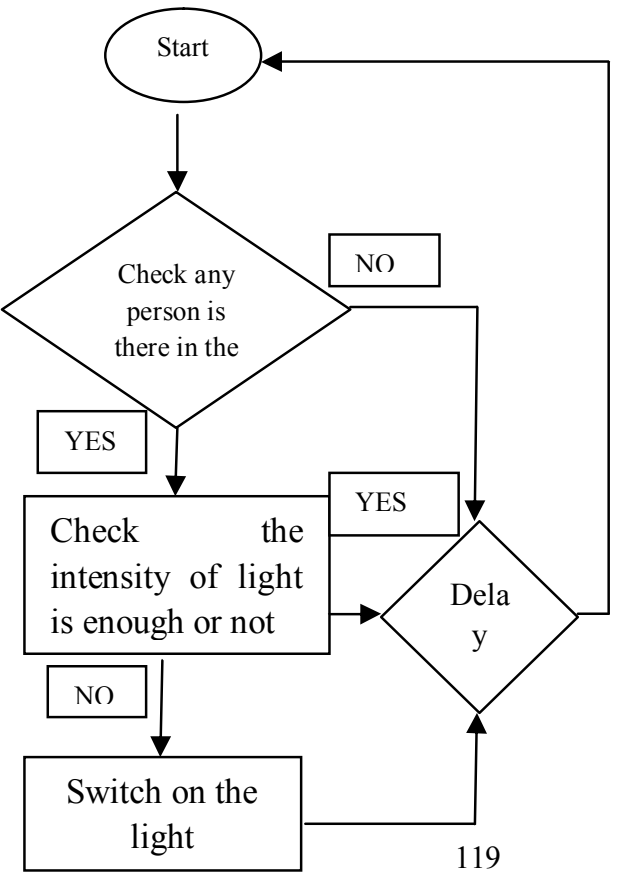




\section{RESULTS:}

The proposed system has been implemented in a room with four lights each of 40 watts. Since it is normal classroom where evening classes are also conducted the intensity required has been set to 500 lux which was set as the reference level in microcontroller. Before implementing this system, around 800 watts of energy was consumed per day. After implementing this system in that room it has been considerably reduced to 480 Watts. Thus on using this system a large amount of energy can be saved.

\section{CONCLUSION FUTURE WORK:}

AND

The proposed system can able to reduce the power consumption to the maximum limit and also this system will help us to keep the working environment in a pleasant and comfortable manner.

In this system the number of persons present in the room (Person counter) can be included and also the data transmission from PIR sensor to microcontroller can be implemented through wireless such that the system will become a scalable one in the sense a single system can able to control a large number of rooms. Apart from these things the system can be upgraded to allow the users to configure the intensity of light in real time.

\section{REFERENCES:}

[1] CIBSE. Reasoning about naming systems. The Chartered Institution of Building Services Engineers, 2002.

[2] Intelligent Energy Conservation System Design Based on Hybrid Wireless Sensor Network Hung-Cheng Chen Department of Electrical Engineering, National Chin-Yi University of Technology, Taiwan, Teng-Fa Tsao Department of Electrical Engineering, Nan Kai University of Technology, Taiwan, Chun-Liang Hsu Department of Electrical Engineering, St. John's University, Taiwan IPCSIT vol. 23 (2012).

[3] Evaluation of Energy-Efficiency in Lighting Systems using Sensor Networks Declan T. Delaney, Gregory M.P. O'Hare, and Antonio G. Ruzzelli CLARITY: Centre for Sensor Web Technologies University College Dublin

[4] Intelligent Lighting System Using Wireless Sensor Networks A.A.Nippun Kumaar , Kiran.G ,Sudarshan TSB Department of Computer Science \& Engineering, Amrita Vishwa Vidyapeetham, School Of Engineering, Bangalore Campus, India IJASUC Vol.1, No.4, December 2010

[5] Microchip Technology Inc. PIC16F877A Datasheet, RevisionC, 2003.

[6]http://www.parallax.com/detail.asp?prod uctid $=555-28027$

[7] Datasheet of NORP 12 LDR 